\title{
Uroflowmetry and Post-Void Urine Volume in the Initial Evaluation of Suspected Obstructive Prostatic Enlargement
}

\author{
Sigiberto II García-Nares ${ }^{1 *}$ and Álvaro José Montiel-Jarquín ${ }^{2}$ \\ ${ }^{1}$ Department of Urology, El Marqués Regional General Hospital, Mexico \\ ${ }^{2}$ Department of Investigation, Traumatology and Orthopedics Hospital (UMAE), Mexico
}

*Corresponding author: Sigiberto II Garcia Nares, Department of Urology, “El Marqués” Regional General Hospital, Mexican Social Service Institute IMSS, Queretaro, Mexico

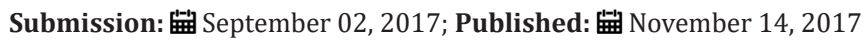

\begin{abstract}
The obstructive prostatic enlargement is the most common benign pathology in men. For its evaluation, it is used the digital rectal exam, questionnaires of the lower urinary tract symptoms, prostate specific antigen and complimentary tools like pelvic and transrectal ultrasound, uroflowmetry, urethrocystogram and urethrocystoscopy. In Mexico, the uroflowmetry is not commonly used for diagnosing obstructive prostatic enlargement.

Objective: To determine the usefulness of the uroflowmetry and residual urine volume in the evaluation of men with suspected obstructive prostatic enlargement in the first visit to the urologist.

Material and methods: Descriptive and cross sectional study in men older than 40 years, who were asked about lower urinary tract symptoms, uroflowmetry and measurement of residual urine volume.

Results: 95 patients with suspected obstructive prostatic enlargement. 25 (26.3\%) patients had non obstructive pattern and 70 (73.7\%) obstructive pattern. In the results of uroflowmetry and ultrasound (combined), 26 (27.4\%) patients were non obstructive and $69(72.6 \%)$ obstructive. The concordance between the uroflowmetry and the final result was 0.812 (Kappa). The correlation between the percentage of residual volume and the final result was $0.644, \mathrm{p}=0.0001$ ( $\rho$ of Pearson) and the correlation between prostate weight and final result was 0.4830 , $p=0.0001$ ( $\rho$ of Pearson).

Conclusion: The uroflowmetry with the International Index of Prostatic Symptoms guide to the severity of prostatic symptoms and with the residual urine volume can help to begin prompt treatment for obstructive prostatic enlargement.
\end{abstract}

Keywords: Uroflowmetry; Post-void residual urine; Obstructive prostatic enlargement.

\section{Introduction}

Uroflowmetry is the initial urodynamic test; it is no invasive and determines the characteristics of urinary flow during micturition; it is used in patients with voiding dysfunction, lower urinary tract symptoms and urinary incontinence [1]. It is underused in countries like Mexico. The evaluation of lower urinary tract dysfunction initially was made with image studies that detected anatomical changes. Later, functional studies measured the pressure as the only parameter, relegating neurogenic dysfunctions [2]. In 1948, William Drake, published the uroflowmetry technique [3], which is an optional study in the initial evaluation of patients with obstructive prostatic enlargement [4]. Uroflowmetry is the electronic registry of urinary flow during micturition; it is a no invasive test, used in patients with lower urinary tract symptoms, which mimics the usual micturition of the patient. Results are not specific for prostatic diseases, other diseases like urethral stenosis and weak contractions of the bladder, offer abnormal results [5].
Uroflowmetry must be used with caution and always with other diagnostic tools like International Prostatic Symptoms Score (IPSS) and transabdominal prostatic ultrasound with post-void urine volume [6]. There is great variability in uroflowmetry parameters, even in healthy patients, because of that it is suggested to use high normal values that diminish specificity but augment sensibility of patients with outlet bladder obstruction. The objective of this study is to determine the usefulness of the uroflowmetry and residual urine volume in the evaluation of men with suspected obstructive prostatic enlargement.

\section{Material and Methods}

Descriptive and cross sectional study from December 2015 to August 2016 in male patients with suspected obstructive prostatic enlargement and moderate to severe IPSS, 40 years or older, without previous prostatic or pelvic surgery, total bladder volume 
of $150-500 \mathrm{ml}$ during the study; patients with previous diagnostic of benign prostatic hyperplasia and arterial systemic hypertension were excluded because drugs for the treatment of these diseases could alter the uroflowmetry results. Patients were invited to participate in the study and those who accepted signed informed consent. Patients were asked about age and urinary symptoms with IPSS questionnaire, transabdominal prostatic ultrasound was used for prostatic volume, bladder capacity and post-void residual urine volume and percentage, uroflowmetry for average flow rate, maximum flow (Qmax) rate, voiding time and flow time.

It was considered non-obstructive result when patients had ultrasound $\leq 10 \%$ post-void residual urine volume and uroflowmetry with Qmax $\geq 15 \mathrm{ml} / \mathrm{min}$; it was considered obstructive result when post-void residual volume $>10 \%$ and $\mathrm{Qmax}<15 \mathrm{ml} / \mathrm{min}$. Uroflowmetry was made with Solar MMS Medical Measurement Systems equipment and post-void residual urine volume with ultrasound Aloka Prosound Alpha 6. Results were collected by the author in Excel program and statistics made with StatCalcfor Mac.

Patients were sent to medical consultation with uroflowmetry results for medical treatment. Statistical analysis was made with descriptive measurements and nominal variables with $\mathrm{x} 2$ and Pearson for correlation.

\section{Results}

Ninety-five patients with suspected obstructive prostatic enlargement were studied. Average age was 64.82 (minimum 47-maximum 83)+8.41 years. IPSS results were: $80(84.2 \%)$ patients with moderate IPSS and 15(15.8\%) with severe IPSS, average point score was 14.94 (minimum 8-maximum 24 ) +4.20 points (Table 1 ).

Table 1: IPSS results.

\begin{tabular}{|c|c|c|}
\hline & Frequency(N) & Percent(\%) \\
\hline Moderate & 80 & 84.2 \\
\hline Severe & 15 & 15.8 \\
\hline Total & 95 & 100 \\
\hline
\end{tabular}

\section{Ultrasound results (Table 2)}

Table 2: Ultrasound results.

\begin{tabular}{|c|c|c|c|c|c|}
\hline & N & Minimum & Maximum & Average & $\begin{array}{c}\text { Standard } \\
\text { deviation }\end{array}$ \\
\hline $\begin{array}{c}\text { Prostate } \\
\text { volume(cc) }\end{array}$ & 95 & 21 & 102 & 56.47 & 16.774 \\
\hline $\begin{array}{c}\text { Pre-voidurine } \\
\text { volume(ml) }\end{array}$ & 95 & 136 & 432 & 234.99 & 71.724 \\
\hline $\begin{array}{c}\text { Post-void } \\
\text { residual } \\
\text { volume(ml) }\end{array}$ & 95 & 0 & 110 & 36.91 & 20.206 \\
\hline $\begin{array}{c}\text { Bladder } \\
\text { capacity(ml) }\end{array}$ & 95 & 164 & 471 & 271.89 & 73.49 \\
\hline $\begin{array}{c}\text { Percentage of } \\
\text { urine residual } \\
\text { volume (\%) }\end{array}$ & 95 & 0 & 44 & 13.43 & 7.636 \\
\hline
\end{tabular}

Average prostatic volume was 56.47 (minimum 21, maximum 102)+16.77 cubic centimeters(cc), average pre-void urine volume was 234.99 (minimum 136, maximum 432) \pm 71.72 milliliter(ml), average post-void residual urine volume was 36.91(minimum 0 , maximum 110) $\pm 20.20 \mathrm{ml}$, average bladder capacity was 271.89 (minimum 164, maximum 471 ) $\pm 73.49 \mathrm{ml}$, with average post-void residual urine volume percentage of 13.43 (minimum 0 , maximum 44$) \pm 7.63 \%$.

\section{Uroflowmetry results (Table 3)}

Table 3: Uroflowmetry results.

\begin{tabular}{|c|c|c|c|c|c|}
\hline & N & Minimum & Maximum & Average & $\begin{array}{c}\text { Standard } \\
\text { Deviation }\end{array}$ \\
\hline $\begin{array}{c}\text { Average } \\
\text { flow } \\
\text { rate(ml/s) }\end{array}$ & 95 & 2 & 19 & 7.47 & 3.758 \\
\hline $\begin{array}{c}\text { Maximum } \\
\text { Flow } \\
\text { rate(ml/s) }\end{array}$ & 95 & 4 & 38 & 14.46 & 7.27 \\
\hline $\begin{array}{c}\text { Voiding } \\
\text { time(s) }\end{array}$ & 95 & 15 & 95 & 39.2 & 17.041 \\
\hline $\begin{array}{c}\text { Flow } \\
\text { time(s) }\end{array}$ & 95 & 15 & 71 & 36.6 & 15.506 \\
\hline N & 95 & & & & \\
\hline
\end{tabular}

Average flow rate was 7.47 (minimum 2, maximum 19) $\pm 3.75 \mathrm{ml} / \mathrm{s}$, average Qmax was 14.46 (minimum 4, maximum $38) \pm 7.27 \mathrm{ml} / \mathrm{s}$, average voiding time was 39.20 (minimum 15 , maximum 95) \pm 17.04 seconds and average flow time was 36.60 (minimum 15 , maximum 71$) \pm 15.50$ seconds. Uroflowmetry results obtained a frequency of $25(26.3 \%)$ non-obstructive patients and $70(73.7 \%)$ obstructive patients. Combined results (uroflowmetry and ultrasound results) obtained 26(27.4\%) nonobstructive patients and $69(72.6 \%)$ obstructive patients. It was obtained Kappa 0.812 between uroflowmetry and combined result (Table 3) with $\mathrm{p}<0.005$. Correlation between post-void residual urine volume percentage and combined result was $\rho=0.64$ $(\mathrm{p}=0.0001)$. Correlation between prostate volume and combined result was $\rho=0.4830, p=0.0001$. Correlation between IPSS result and uroflowmetry result was $\rho=0.486(p=0.0001)$.

\section{Discussion}

Lower urinary tract symptoms are consequence of obstructive prostatic enlargement which is a common disease in old men, it is common in all ethnic groups [7-9]. In the present study, the average age was 64.82 years which is similarly to the results of international literature $[10,11]$. Many of the patients were apparently healthy, which gave normal and abnormal results. The diagnostic of prostatic enlargement and lower urinary tract symptoms must include the IPSS questionnaire which is a scoring system used to screen for and diagnose obstructive prostatic enlargement as well as to monitor symptoms and guide decisions about how to manage the disease. The IPSS is based on the answers to eight questions, seven regarding disease symptoms and one question related to the patient's quality of life. It can be divided in mild(0- 
7 points), moderate(8-19 points) or severe(20-35 points) [12]. In this study, average IPSS score was 14.94 points; $84.2 \%$ patients had moderate IPSS and $15.8 \%$ severe IPSS, which shows that most of the patients go to medical consultation with moderate symptoms. In a Japanese study the average IPSS was 6.9 points [13]. Normal prostate volume is $15-20 \mathrm{cc}$, total bladder volume is $300-600 \mathrm{ml}$ and post-void residual urine volume percentage $<10 \%$ [14]. In this study average prostate volume was $56.47+16.77 \mathrm{cc}$. However, we did not find any study that mentions the average prostatic volume in population with suspected obstructive prostatic enlargement, on the other hand there are studies in Japan about healthy population with average prostate volume of $18.5+5.2 \mathrm{cc}$ [13].

Nowadays, uroflowmetry is a diagnostic tool that is used with post voided urine volume in Urodynamics units; none the less it is not standardized in the evaluation of patients with lower urinary tract symptoms or in patients with suspected obstructive prostatic enlargement [15]. Abrahms, Siroky and Schaffer reported that maximum flow (Qmax) is the most important fact obtained from uroflowmetry, when Qmax is diminished it can be because of obstruction or diminished contraction of detrusor muscle [16]. Normal uroflowmetry parameters are: Qmax $\geq 15 \mathrm{ml} / \mathrm{s}((30 \pm 12 \mathrm{ml} / \mathrm{s})$, flow rate $17 \pm 8 \mathrm{ml} / \mathrm{s}$, voiding time $25-40$ s, flow time $20 \pm 10$ s) [16]. Patients with lower urinary tract symptoms were included, with the next results: average flow rate 7.47 (minimum 2, maximum 19) $\pm 3.75 \mathrm{ml} / \mathrm{s}$, average Qmax was 14.46 (minimum 4, maximum 38 ) $\pm 7.27 \mathrm{ml} / \mathrm{s}$; average voiding time was 39.20 (minimum 15 , maximum 95 ) \pm 17.04 seconds and average flow time was 36.60 (minimum 15 , maximum 71 ) \pm 15.50 seconds. As expected, these results differ from normal values because of the patients included. An abnormal uroflowmetry suggests abnormal micturition and the objective is early detection of bladder outlet obstruction and offer prompt treatment to avoid bladder dysfunction or complications as acute urine retention or kidney failure [6]. Outcomes in this study were: $26.3 \%$ non-obstructive patients and $73.7 \%$ obstructive patients.

It was obtained a perfect or almost perfect concordance (0.812, Kappa) [17], between uroflowmetry and combined result (uroflowmetry + transabdominal prostatic ultrasound), which means that uroflowmetry is useful in patients with suspected obstructive prostatic enlargement. Correlation among post-void residualurine volume and combined result $0.644, \mathrm{p}=0.0001$ and correlation among prostate volume and combined result was $0.4830, p=0.0001$, while correlation among IPSS and uroflowmetry was $0.486, \mathrm{p}=0.0001$ (Pearson's $\rho$ ).

\section{Conclusion}

The uroflowmetry with the International Index of Prostatic Symptoms and post voided urine volume guide to the severity of prostatic symptoms and help to define the prompt treatment for obstructive prostatic enlargement. Uroflowmetry can be considered a valuable tool in the initial evaluation of patients with suspected obstructive prostatic enlargement. Uroflowmetry is underused in countries like Mexico.

\section{References}

1. Parekh DJ, Pope JC, Adams MC, Brock JW (2001) The use of radiography, urodynamic studies and cystoscopy in theevaluation of voiding dysfunction. J Urol 165(1): 215-218.

2. Chapple CR, Roehrborn CG (2006) A shifted paradigm for the further understanding, evaluation, and treatment of lower urinary tract symptoms in men: focus on the bladder. Eur Urol 49(4): 651-658.

3. Drake WM (1948) The uroflowmeter: an aid to the study of the lower urinary tract. J Urol 59: 650-658.

4. Sonke GS, Kortmann BB, Verbeek AL, Kiemeney LA, Debruyne FM, et al. (2000) Variability of pressure-flow studies in men with lower urinary tract symptoms. Neurourol Urodyn 19(6): 637-651.

5. Eri LM, Wessel N, Berge V (2001) Test-retest variation of pressure flow parameters in men with bladder outlet obstruction. J Urol 165(4): 11881192.

6. Zambon JP, Sivonei N, Karam AJ, Conceição RD, Carvalho JA, et al. (2013) Uroflowmetry in a Large Population of Brazilian Men Submitted to a health check up program and its correlation with IPSS and prostate size. Int Braz J Urol 39(6): 841-846.

7. Donovan JL, Kay HE, Peters TJ, Abrams P, Coast J, et al. (1997) Using the ICSQoL to measure the impact of lower urinary tract symptoms on quality of life: evidence from the ICS-'BPH' study. Br J Urol 80(5): 712721.

8. Oesterling JE, Jacobsen SJ, Chute CG, Guess HA, Girman CJ, et al. (1993) Serum prostate specific antigen in a community-based population of healthy men: establishment of age-specific reference ranges. JAMA 270(7): 860-864.

9. Vesely S, Knutson T, Damber JE, Dicuio M, Dahlstrand C (2003) Relationship between age, prostate volume, prostate-specific antigen, symptom score and uroflowmetry in men with lower urinary tract symptoms. Scand J Urol Nephrol 37(4): 322-328.

10. Madersbacher S, Alivizatos G, Nordling J, Sanz CR, Emberton M, et al. (2004) EAU 2004 guidelines on assessment, therapy and follow-up of men with lower urinary tract symptoms suggestive of benign prostatic obstruction. Eur Urol 46(5): 547-554.

11. Maldonado-AE, Moreno-AO, Neri-PE (2009) Clinical Guidelines: Diagnosis and treatment of benign prostatic hiperplasia. Mexican Surgery Association.

12. Roehrborn CG, Sech S, Montoya J, Rhodes T, Girman CJ (2001) Interexaminer reliability and validity of a three-dimensional model to assess prostate volume by digital rectal examination. Urology 57(6): 1087-1092.

13. Fukuta F, Masumori N, Mori M, Tsukamoto T (2012) Natural history of lower urinary tract symptoms in Japanese men from a 15-year longitudinal community-based study. BJU Int 110(7): 1023-1029.

14. Spanish Urodynamics Group \& SINUG (2005) Consensus about terminology and concepts of lower urinary tract function. Actas Urol Esp 29(1): 16-30.

15. Abrams P, Cardozo L, Fall M, Griffiths D, Rosier P, et al. (2002) The standardization of terminology in lower urinary tract function. Neurourol Urodyn 21(2): 167-178.

16. Abrams P, Bruskewitz R, de-La-Rossette J, Griffiths D, Koyanagi T, et al. (1995) The diagnosis of bladder outlet obstruction: urodynamics. Proceedings, the $3^{\text {rd }}$ Consultation on BPH. World Health Organization, Geneva, Switzerland, pp. 299-367.

17. Montiel-JAJ, Pérez-RS, Núñez-GR, Barragán-HR, Rodríguez-PL, et al. (2015) Concordance level between 3D- tomographic reconstructions and surgical results in facial traumatic fractures. Pren Med Arg 101(9): 491-496. 